\title{
THE MECHANISM OF HYPERCHOLESTEREMIA INDUCED BY THE INGESTION OF FAT
}

\author{
KEIKO HATA,* SUMIKO NAGAO,* FUMIE NAKAMURA,* \\ and YASUMASA MAJIMA \\ Institute of Nutrition, School of Medicine \\ Keio University, Tokyo, Japan
}

(Received for publication February 12, 1969)

\section{INTRODUCTION}

The cause of the increase of serum cholesterol by the ingestion of saturated fatty acids and the invariability of that by the ingestion of polyunsaturated fatty acids are not yet clear.

The change of serum cholesterol seems from the theory to be due to the following four causes: 1) promotion and inhibition of cholesterol degradation to bile acids, 2) transfer of circulating cholesterol rich lipoprotein to another body pool, 3) promotion and inhibition of cholesterol synthesis, 4) restriction of cholesterol intake or interference with its absorption or reabsorption.

Lewis et $a l^{1-3}$ described that the diet rich in polyunsaturated fatty acids promoted the excretion of bile acid. However, Spritz et al4 described that the excretion of bile acids did not increase and the transfer of circulating cholesterol might concern with the change of the serum cholesterol. Kinsell et $a l^{5}$ reported that the serum cholesterol lowering action of polyunsaturated fatty acids (the action to maintain the normal level of the serum cholesterol) might be due to the inhibition of the synthesis of cholesterol.

Recently, Tidwell et $a l^{6}$ reported that the diets rich in saturated fatty acids promoted the cholesterol synthesis from acetic acid in the liver. We investigated whether the ingestion of saturated fatty acids and polyunsatulated fatty acids concerned the degradation and synthesis of cholesterol using rats, and will report that results.

* Musasino Women's University. 


\section{EXPERIMENT}

1. Male rats weighing about $200 \mathrm{~g}$ were divided into 10 groups consisting of 5 rats in a group. The rats from the first to the fifth groups were fed by the cholesterol palmitic acid diet and from the sixth to the tenth groups by the cholesterol linoleic acid diet. After feeding for two weeks, the rats from the first to the fifth groups were administered $9.5 \mu \mathrm{c}-12.5 \mu \mathrm{c}$ of $1-\mathrm{C}^{14}$ palmitic acid $\left(3.90 \times 10^{5}\right.$ c.p.m.- $5.12 \times 10^{5}$ c.p.m. $)$ dissolved in $1.9 \mathrm{~g}-2.5 \mathrm{~g}$ of palmitic acid and $0.4 \mathrm{~g}-0.5 \mathrm{~g}$ of cholesterol simultaneously. Saturated fatty acids and unsaturated fatty acids of the serum cholesterol esters in the liver were determined using of our method ${ }^{7}$ after 3 hours following administration in the first group, 6 hours in the second group, 12 hours in the third group, 24 hours in the fourth group and 48 hours in the fifth group, and their specific activities were determined by a gas G.M. counter.

Cholesterol Palmitic Acid Diet

\begin{tabular}{lclc}
\hline \hline Kasein* & $14 \mathrm{~g}$ & D $_{\mathbf{s}}$ & $400 \mathrm{I}$. U. \\
Sucrose & $39 \mathrm{~g}$ & Ascorbic acid & $75 \mathrm{mg}$ \\
Starch & $40 \mathrm{~g}$ & Pyridoxine & $3 \mathrm{mg}$ \\
M. Salz & $4 \mathrm{~g}$ & $\alpha$-Tocopherol & $2 \mathrm{mg}$ \\
Palmitic acid & $1.5 \mathrm{~g}$ & B $_{12}$ & $0.002 \mathrm{mg}$ \\
Cholesterol & $1.5 \mathrm{~g}$ & Niacin & $20 \mathrm{mg}$ \\
A & $3,000 \mathrm{I} . \mathrm{U}$. & Pantothenic acid & $1 \mathrm{mg}$ \\
Thiamin-HCl & $2 \mathrm{mg}$ & K & $0.4 \mathrm{mg}$ \\
B $_{2}$ & $3 \mathrm{mg}$ & Choline & $0.1 \mathrm{~g}$ \\
\hline
\end{tabular}

* Whashed by the warmed methanol and ether.

Linoleic acid was used for the cholesterol linoleic acid diet in place of palmitic acid.

The rats from the sixth to the tenth groups were administered $7.1 \mu \mathrm{C}-$ $125 \mu \mathrm{C}\left(3.43 \times 10^{5}\right.$ c.p.m. $-6.04 \times 10^{5}$ c.p.m. $)$ of 1 - $\mathrm{C}^{14}$ linoleic acid dissolved in $1.4 \mathrm{~g}-2.5 \mathrm{~g}$ of linoleic acid and $0.3 \mathrm{~g}-0.5 \mathrm{~g}$ of cholesterol simultaneously. The determination of specific activities of fatty acids of the serum cholesterol esters in the liver was carried out as the same procedure as that described above, after 3 hours following administration in the sixth group, 6 hours in the seventh group, 12 hours in the eighth group, 24 hours in the nineth group and 48 hours in the tenth group.

2. Rats were divided into 18 groups in a similar fashion of the above experiment. Cholesterol was removed from the above mentioned palmitic acid diet. The first group was fed by the diet with palmitic acid in $10 \%$ and 
administered by $9.0 \mu \mathrm{C}-10.0 \mu \mathrm{C}$ of $1-\mathrm{C}^{14}$ glucose. The second group was fed by the diet with oleic acid in $10 \%$ and administered $6.6 \mu \mathrm{C}-10.0 \mu \mathrm{C}$ of $1-\mathrm{C}^{14}$ glucose. The third group was fed by the diet with linoleic acid in $10 \%$ and administered $5.4 \mu \mathrm{C}-10.0 \mu \mathrm{C}$ of $1-\mathrm{C}^{14}$ glucose. The fourth group was administered $5.4 \mu \mathrm{C}-10.0 \mu \mathrm{C}$ of $1-\mathrm{C}^{14}$ palmitic acid dissolved in $10 \%$ palmitic acid. The fifth group was administered $63 \mu \mathrm{C}-10.0 \mu \mathrm{C}$ of $1-\mathrm{C}^{14}$ oleic acid dissolved in $10 \%$ oleic acid. The sixth group was administered $4.3 \mu \mathrm{C}-10.0 \mu \mathrm{C}$ of $1-\mathrm{C}^{14}$ linoleic acid dissolved in $10 \%$ linoleic acid. The seventh group was administered $6.3 \mu \mathrm{C}-10.0 \mu \mathrm{C}$ of $1-\mathrm{C}^{14}$ glucose after 2 weeks of feeding with the diet with palmitic acid in $10 \%$. The eighth group was administered $7.2 \mu \mathrm{C}$ $10.0 \mu \mathrm{C}$ of $1-\mathrm{C}^{14}$ glucose after 2 weeks of feeding with the diet with oleic acid in $10 \%$. The nineth group was administered $6.0 \mu \mathrm{C}-10.0 \mu \mathrm{C}$ of $1-\mathrm{C}^{14}$ glucose after 2 weeks feeding with the diet with linoleic acid in $10 \%$. The tenth group was administered $7.8 \mu \mathrm{C}-10.0 \mu \mathrm{C}$ of $1-\mathrm{C}^{14}$ palmitic acid after 2 weeks of feeding with the diet with palmitic acid in $10 \%$. The eleventh group was administered $81 \mu \mathrm{C}-10.0 \mu \mathrm{C}$ of $1-\mathrm{C}^{14}$ oleic acid after 2 weeks of feeding with the diet with oleic acid in 10\%. The twelfth group was administered $5.4 \mu \mathrm{C}-10.0 \mu \mathrm{C}$ of $1 . \mathrm{C}^{14}$ linoleic acid after 2 weeks of feeding with the diet with linoleic acid in $10 \%$. The thirteenth group was administered $8.1 \mu \mathrm{C}-$ $10.0 \mu \mathrm{C}$ of $1-\mathrm{C}^{14}$ glucose after 4 weeks of feeding with the diet with palmitic acid in $10 \%$. The fourteenth group was administered $9.0 \mu \mathrm{C}-10.0 \mu \mathrm{C}$ of 1-C ${ }^{14}$ glucose after 4 weeks of feeding with the diet with oleic acid in $10 \%$. The fifteenth group was administered $5.4 \mu \mathrm{C}-10.0 \mu \mathrm{C}$ of $1-\mathrm{C}^{14}$ glucose after 4 weeks of feeding with the diet with linoleic acid in $10 \%$. The sixteenth group was administered $9.0 \mu \mathrm{C}-10.0 \mu \mathrm{C}$ of $1-\mathrm{C}^{14}$ palmitic acid after 4 weeks of feeding with the diet with palmitic acid in $10 \%$. The seventeenth group was administered $6.9 \mu \mathrm{C}-10.0 \mu \mathrm{C}$ of $1-\mathrm{C}^{14}$ oleic acid after 4 weeks of feeding with the diet with oleic acid in 10\%. The eighteenth group was administered $6.3 \mu \mathrm{C}-10.0 \mu \mathrm{C}$ of $1-\mathrm{C}^{14}$ linoleic acid after 4 weeks of feeding with the diet with linoleic acid in 10\%. In each group, after 3 days following administration, the specific activity of total cholesterol in the liver and the serum to the daily dosage was determined.

3. The separation of cholesterol from the liver and the serum:

The liver or the serum was extracted with methanol-ether $(3: 1)$ and the extract was saponificated. Unsaponificated fraction was separated by petroleum-ether washed with $\frac{N}{5}$ KOH methanol solution and was subjected to chromatography of woelm neutral almina. The woelm neutral almina was 


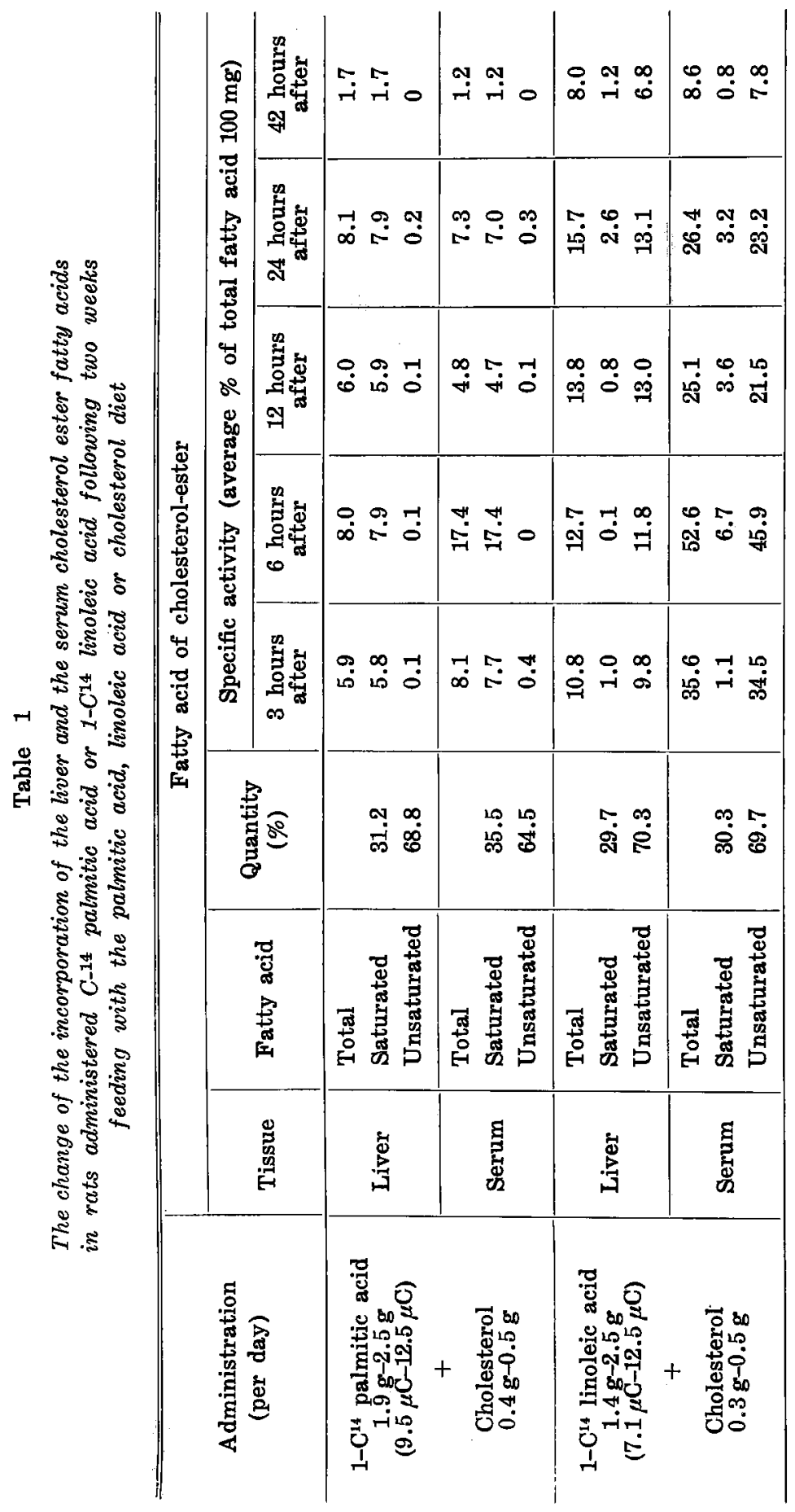


washed with water, dried at $100^{\circ} \mathrm{C}$ for 6 hours and was packed into an absorption tube using petroleum-ether. The tube was eluated by $1 \%$ methanolpetroleum-ether, followed by 5\% methanol-petroleum-ether for the fractionary separation.

\section{RESULT AND DISCUSSION}

The specific activity of fatty acids of cholesterol esters in the liver and the serum was determined after $3,6,12,24$, or 48 hours following administration of 1-C ${ }^{14}$ palmitic acid and cholesterol or 1-C ${ }^{14}$ linoleic acid and cholesterol in rats which had been fed with the cholesterol-palmitic acid diet or the cholesterol-linoleic acid diet for 2 weeks. The result is shown in Table 1.

There were no great differences of the specific activity of the total fatty acid in the serum between the administration of 1-C14 palmitic acid and that of 1-C ${ }^{14}$ linoleic acid. The values of both groups got maximum at the sixth hour and decreased in a same degree. In the liver, the decrease of the specific activity in course of time was lower in the gorup of $1-\mathrm{C}^{14}$ linoleic acid than in the group of palmitic acid. Saturated fatty acids in the liver and in the serum slightly decreased in course time in the groups administered 1-C14 linoleic acid. However, the levels of unsaturated fatty acids in the liver and the serum were nearly zero in the groups administered $1-\mathrm{C}^{14}$ palmitic acid.

Therefore, the rate of degradation of cholesterol ester in the liver was not changed by the administration of palmitic acid or linoleic acid. Fatty acids in cholesterol esters seem to be hardly subjected to unsaturation and to be subjected to saturation. We reported that unsaturated fatty acids in the liver cholesterol esters decreased larger when cholesterol-linoleate was ingested than when cholesterol-palmitate was ingested. 8 It may be due to the saturation of fatty acids in the liver cholesterol esters.

Next, an experiment to investigate whether the change of the serum cholesterol concerned the cholesterol synthesis in the liver was carried out. Rats were fed by the diet containing palmitic acid, oleic acid and linoleic acid for 2 or 4 weeks and then administered 1-C $\mathrm{C}^{14}$ glucose, 1-C ${ }^{14}$ palmitic acid, 1-C ${ }^{14}$ oleic acid and 1-C $\mathrm{C}^{14}$ linoleic acid for 3 days, and the specific activities of the liver and serum cholesterols were determined. The result is shown in Table 2.

At the start, the specific activities of cholesterols in the livers and the sera of rats administered 1-C ${ }^{14}$ palmitic acid were about three times those 
Table 2

The incorporation of fatty acid with the liver and the serum cholesterol in rats administer 1-C $C^{14}$ glucose, 1-C $C^{14}$ palmitic acid, 1-C14 oleic acid and 1-C $C^{14}$ linoleic acid following two or four weeks feeding with the palmitic acid, linoleic acid or cholesterol diet*

\begin{tabular}{|c|c|c|c|c|c|}
\hline \multirow{2}{*}{ Tissue } & \multirow{2}{*}{$\begin{array}{l}\text { Diet } \\
\text { (added 10\%) }\end{array}$} & \multirow{2}{*}{$\mathrm{C}^{14}$ administration } & \multicolumn{3}{|c|}{$\begin{array}{l}\text { Specific activity of cholesterol } \\
\text { (average } \% \text { of } 100 \mathrm{mg} \text { ) }\end{array}$} \\
\hline & & & Start & $\begin{array}{l}2 \text { weeks } \\
\text { feedings }\end{array}$ & $\begin{array}{l}4 \text { weeks } \\
\text { feedings }\end{array}$ \\
\hline \multirow{6}{*}{ Liver } & Palmitic acid & 1-C' glucose & 1.4 & 1.0 & 1.1 \\
\hline & Oleic acid & 1-C' glucose & 1.3 & 1.0 & 0.6 \\
\hline & Linoleic acid & 1-C $\mathbf{C}^{14}$ glucose & 1.0 & 1.2 & 1.3 \\
\hline & Palmitic acid & 1-C $\mathrm{C}^{14}$ palmitic acid & 3.3 & 8.3 & 4.0 \\
\hline & Oleic acid & $1-\mathrm{C}^{14}$ oleic acid & 2.2 & 8.0 & 3.7 \\
\hline & Linoleic acid & 1-C $\mathrm{C}^{14}$ linoleic acid & 0.7 & 1.4 & 2.1 \\
\hline \multirow{6}{*}{ Serum } & Palmitic acid & $1-C^{14}$ glucose & 1.2 & 0.9 & 1.2 \\
\hline & Oleic acid & $1-C^{14}$ glucose & 1.5 & 0.8 & 1.7 \\
\hline & Linoleic acid & $1-\mathrm{C}^{14}$ glucose & 1.0 & 0.9 & 1.2 \\
\hline & Palmitic acid & $1-C^{14}$ palmitic acid & 2.6 & 8.3 & 5.3 \\
\hline & Oleic acid & $1-C^{14}$ oleic acid & 2.4 & 7.9 & 4.2 \\
\hline & Linoleic acid & 1-C $\mathrm{C}^{14}$ linoleic acid & 1.4 & 1.9 & 2.0 \\
\hline
\end{tabular}

* The specific activity to the dosage per day.

of rats administered 1-C $\mathrm{C}^{14}$ glucose, and those of 1-C14 oleic acid administered rats were about twice those of $1-\mathrm{C}^{14}$ glucose administered rats. The specific activities in rats administered $1-\mathrm{C}^{14}$ linoleic acid were less than those in rats administered $1-\mathrm{C}^{14}$ glucose.

After 2 or 4 weeks, the specific activities in the livers and the sera of rats administered 1-C ${ }^{14}$ palmitic acid strikingly increased (two or three times), and those in rats administered $1-\mathrm{C}^{14}$ oleic acid increased. However, the activities in rats administered 1-C ${ }^{14}$ linoleic acid or $1-\mathrm{C}^{14}$ glucose did not increase.

It is known that cholesterol is synthesized from acetic acid.9,10 Acetic acid may be synthesized mainly from glucose and fatty acids. Table 2 showed that the amount of synthesized cholesterol from glucose and linoleic acid was not changed and that from palmitic acid or oleic acid increased. 
Therefore, the major cause of the increase of the serum cholesterol by the ingestion of the large amount of palmitic acid may be the increase of the synthesis of cholesterol from palmitic acid (through acetic acid). The major cause that the serum cholesterol does not increase by the administration of the large amount of linoleic acid may be that the synthesis of cholesterol from linoleic acid is not promoted.

\section{SUMMARY}

The specific activities of fatty acid of cholesterol esters in the liver and the serum of rats which were administered $\mathrm{C}^{14}$ palmitic acid and cholesterol or $\mathrm{C}^{14}$ linoleic acid and cholesterol after 2 weeks feeding with the diet containing cholesterol palmitic acid or cholesterol linoleic acid were determined, and the specific activities of cholesterols in the livers and the sera of rats which were administered $\mathrm{C}^{14}$ glucose, $\mathrm{C}^{14}$ palmitic acid, $\mathrm{C}^{14}$ oleic acid or C14 linoleic acid for 3 days after 2 or 4 weeks of feeding with the diet containing palmitic acid, oleic acid or linoleic acid were also determined. There were no differences of the rates of degradation of cholesterol between rats administered palmitic acid and that administered linoleic acid. The synthesis of cholesterol was promoted in course of day by the administration of palmitic acid or oleic acid, but those from linoleic acid and glucose did not increase.

From these results, it is considered that the hypercholesteremia by the ingestion of the large amount of saturated fatty acids is mainly due to the promotion of the cholesterol synthesis from saturated fatty acids and the invariability of the serum cholesterol by the ingestion of polyunsaturated fatty acids (to maintain the normal level) is mainly due to that the cholesterol synthesis from linoleic acid does not increase.

\section{REFERENCES}

1. Goldsmith, G.A., Hamilton, J.G., and Miller, O.N. (1960) Lowering of serum lipid concentration. Arch. Int. Med. 105: 512.

2. Lewis, B. (1958) Effect of certain dietary oils on bile acid secretion and serum cholesterol. Lancet 1: 1090.

3. Gordon, H.B., Lewis. B., Eales, L., and Brock, J.F. (1957) Dietary fat and cholesterol metabolism. Fecal elimination of bile acids and other lipids. Lancet 1: 1299.

4. Spritz, M., Grunday, S., and Ahrens, E.H., Jr. (1963) Studies on the mechanism of diet induced alterations of plasma cholesterol, J. Clin. Invest. 42: 981. 
5. Kinsell, L.W., Michaels, G.D., Frisky, R.W., and Splitter, S. (1957) Fourth international conference on biochemical problems of lipids. Academic Press, New York 125.

6. Pawer, S.S. and Tidwel, H.C. (1967) Effect of fat and cholesterol ingestion upon formation and storage of lipids and cholesterol from acetate-1-C14. Proc. Soc. Exp. Biol. Med. 125: 352.

7. Majima, Y. and Kurihara, F. (1963) Separation and determination of fat. J. Jap. Soc. Food Nutrition 16: 280. (in Japanese)

8. Majima, Y., Nakamura, F., Nagao, S., Kudo, E. and Hata, K. (1968) Influence of dietary cholesterol on the fatty acid composition in cholesterol ester. J. Jap. Soc. Food Nutrition 20: 492. (in Japanese)

9. Swell, L., Trout, E.C., Jr., Field, H., Jr., and Treadwell, C.R. (1958) The role of lymph cholesterol in the regulation of endogenous cholesterol and cholesterol ester synthesis. J. Biol. Chem. 230: 631.

10. Mead, J F. and Fillerup, D.L. (1957) The transpor: of fatty acids in the bloorl. J. Biol. Chem. 227: 1009. 